\title{
PNEUMOCYSTIS CARINII PNEUMONIA AND CONGENITAL HYPOGAMMAGLOBULINAEMIA
}

BY

\author{
W. C. MARSHALL, H. J. WESTON* and MARTIN BODIAN $\dagger$ \\ From The Hospital for Sick Children, Great Ormond Street, London
}

(RECEIVED FCR PUBliCATION AUGUST 12, 1963)

A type of pneumonia due to the protozoon Pneumocystis carinii has been recognized in Europe for many years. There is frequent association with interstitial plasma cell pneumonia. Premature infants and debilitated full-term infants are chiefly affected, with peak incidence of infection occurring between 6 weeks and 4 months (Gajdusek, 1957).

In recent years sporadic cases have been reported in Great Britain, the United States, Canada and Australia. Reports are increasing, but they differ in some respects from the European cases. Older children seem to be affected and there is frequent association with congenital hypogammaglobulinaemia. There have been no reported survivors in cases outside Europe.

The purpose of this report is to present two further cases of Pneumocystis carinii pneumonia, which were associated with hypogammaglobulinaemia. One of them appears to have responded to treatment with the aromatic diamidine, pentamidine.

\section{Methods}

Total Serum Proteins. These were estimated by the Biuret reaction (Wilkinson, 1960).

Paper Electrophoresis. This was according to the method of Flynn and de Mayo (1951) and was qualitative (Fig. 1).

Serum $\gamma$-globulin and $\gamma$-macroglobulin were estimated by a gel diffusion precipitin technique (Soothill, 1962).

Iso-haemagglutinin Titres. The titres were performed by the method described by Mollison (1956).

\section{Case Reports}

Case 1. The third son of young, healthy parents he was born weighing $10 \mathrm{lb}$. (4,535 g.) after an uneventful full-term pregnancy. The neonatal period was normal. There was a family history of hypogammaglobulinaemia.

\footnotetext{
* Present address: Kelvin Chambers, 12 Bolton Street, Wellington, New Zealand.

$\dagger$ Dr. Bodian died on September 25, 1963.
}

One brother died of generalized vaccinia (Galloway and McBean, 1956; 1958); the second died at 11 months from a respiratory illness which was subsequently found to be due to Pneumocystis carinii pneumonia (McKay and Richardson, 1959). This fact was unknown during our patient's illness.

He was seen by Dr. Philip Evans from the age of 2 months because of this family history. Serial paper electrophoresis showed a progressive fall in the circulating gamma globulin. At the age of 6 months the level was found to be $100 \mathrm{mg} . / 100 \mathrm{ml}$. by the gel diffusion precipitin technique. On June 22, 1959, treatment was begun with gamma globulin in the dosage recommended by the Medical Research Council Working Party on hypogammaglobulinaemia, namely, weekly injections of $0.025 \mathrm{~g} . / \mathrm{kg}$. following an initial dose of $0.25 \mathrm{~g} . / \mathrm{kg}$. given in divided doses over the first week.

At 6 months he was said to make grunting noises and to cough occasionally during feeds. During these episodes he became exhausted and pale. There was recent failure to gain weight. In spite of this history, repeated physical examination failed to reveal any abnormality. Chest radiograph showed no abnormality. At $6 \frac{1}{2}$ months the cough became more frequent and mild cyanosis was present. There was a slight

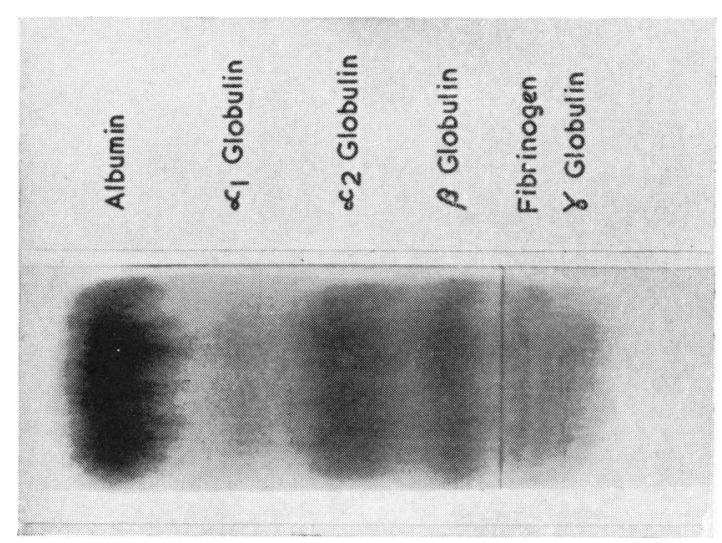

Fig. 1.-Paper electrophoresis strip of plasma proteins of Case 2, aged 2 years, showing apparently normal concentration of globulin. 


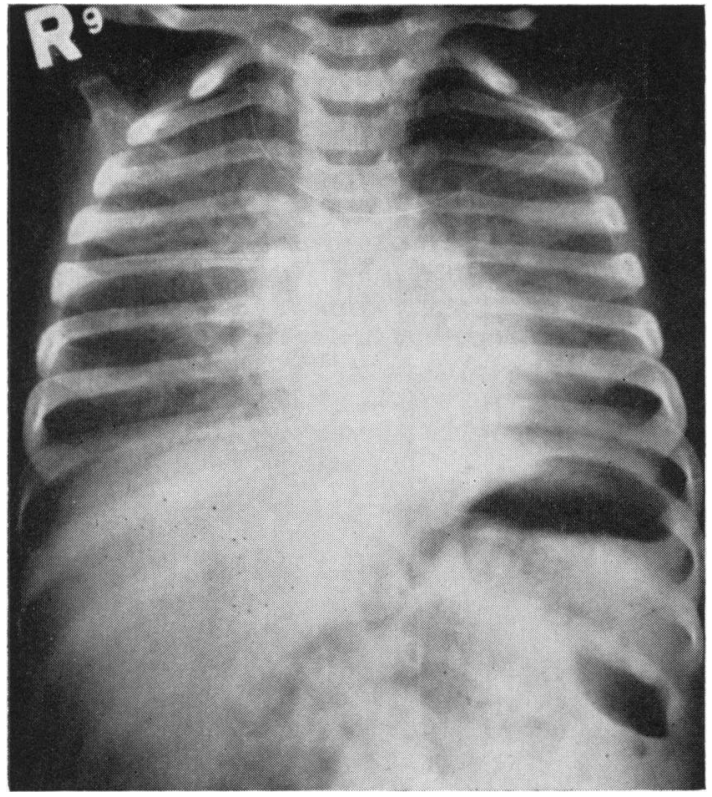

FIG. 2.--Radiograph of Case 1, showing diffuse consolidation of the lungs.

increase in the respiratory rate and the temperature was $99 \cdot 4^{\circ} \mathrm{F} .\left(37 \cdot 3^{\circ} \mathrm{C}.\right)$

Rapid progression of symptoms occurred over the next four days. There was tachypnoea (50-80 per minute), recession of soft parts, expiratory grunt and aggravation of the cyanosis by episodes of coughing. A mild fever was present $\left(99^{\circ}-101^{\circ} \mathrm{F}\right.$.) $\left(37 \cdot 2^{\circ}-38 \cdot 3^{\circ} \mathrm{C}\right.$. $)$. The fingers were clubbed. The percussion note of the chest and the breath sounds were normal. There was no coryza. The blood pressure was $110 / 70 \mathrm{~mm}$. $\mathrm{Hg}$ and no cardiac enlargement was detected; the heart sounds were rapid $(120-200 / \mathrm{min}$.) and no murmurs were heard. Neither hepatosplenomegaly nor lymphadenopathy was found. Radiographs showed progressive changes from patchy consolidation to a diffuse consolidation (Fig. 2), most striking in the hilar region. An 'air bronchogram' was present. The disparity between the extreme respiratory distress, the absence of abnormal signs in the chest and the radiological changes, suggested a diagnosis of Pneumocystis carinii pneumonia.

During the next three weeks there were periods of more severe respiratory distress. Cyanosis became worse during bouts of coughing and even when lifting the flap of the oxygen tent in which he was nursed. Repeated cough swabs failed to reveal any pathogens. No abnormal cells were seen in the gastric washings and tubercle bacilli were not cultured.

Periodic diarrhoea was very troublesome but no pathogens were detected on stool culture.

Treatment with tetracycline, penicillin, novobiocin, nystatin, prednisolone, increased doses of gamma globulin (on July 7, 1959, the serum gamma globulin

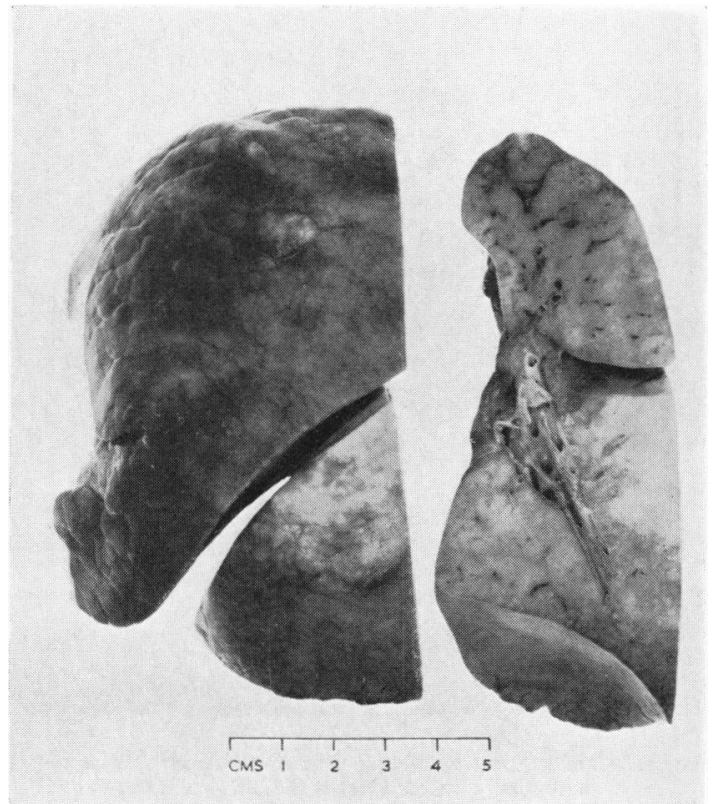

FiG. 3.-Case 1. External and cut surface of left lung to show the liver-like consolidation and the empty bronchial tubes.

was $160 \mathrm{mg} . / 100 \mathrm{ml}$.) and intraperitoneal injection of foetal tissue (mixed liver, lymph nodes and spleen) was not effective. Death occurred during one of the bouts of coughing.

\section{AuTOPSY.}

Respiratory system. There was no gross abnormality on examination of the upper respiratory system, but both lungs were voluminous, pinkish grey in colour and liverlike in consistency. The combined weight was $460 \mathrm{~g}$. compared with a normal weight of $90 \mathrm{~g}$. for the age. The cut sections of the lungs showed the appearances usually associated with pancreas or liver (Fig. 3). Bronchi and bronchioles were quite clear and stood out remarkably well against the background of consolidated lung parenchyma. The thymus was exceedingly small. The spleen was slightly enlarged, firm and deep red in colour. Malpighian follicles were well marked. The liver was grossly enlarged with a smooth capsular surface and weighed $412 \mathrm{~g}$. Its cut surface was pale. No abnormality was found in the pancreas, adrenals, kidneys, cardiovascular or central nervous system.

Histology. Lung sections (Figs. 4 and 5) showed considerable distension of practically all alveoli with a serous exudate of honeycomb appearances in which numerous pneumocystis organisms were demonstrated by a special silver impregnation stain. Bronchi and bronchioles were empty and normal. The interstitial septa were moderately cellular and thickened owing mainly to histiocytic infiltration. Plasma cells were not present, and lymphocytes were scanty. 


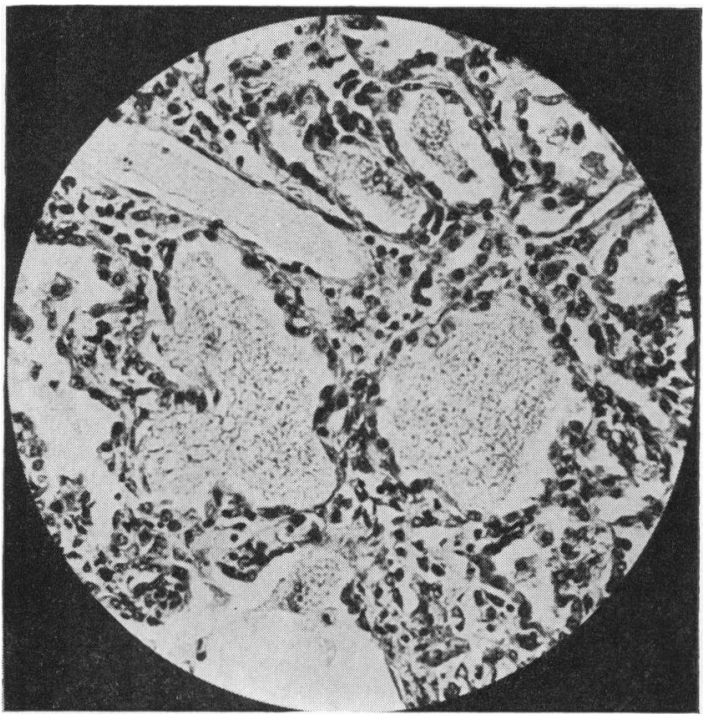

FIG. 4.-Case 1. Section of lung, showing interstitial pneumonitis and honeycomb exudate in alveoli. ( $\times$ 155.)

An extensive, mainly perilobular, fatty change was present in the liver. Lymph nodes from various sites and the thymus showed gross depletion of lymphocytes and no plasma cells. The spleen showed involution of germ centres, but the Malpighian follicles were of normal size. Plasma cells were absent from the bone marrow. The other tissues showed no relevant changes.

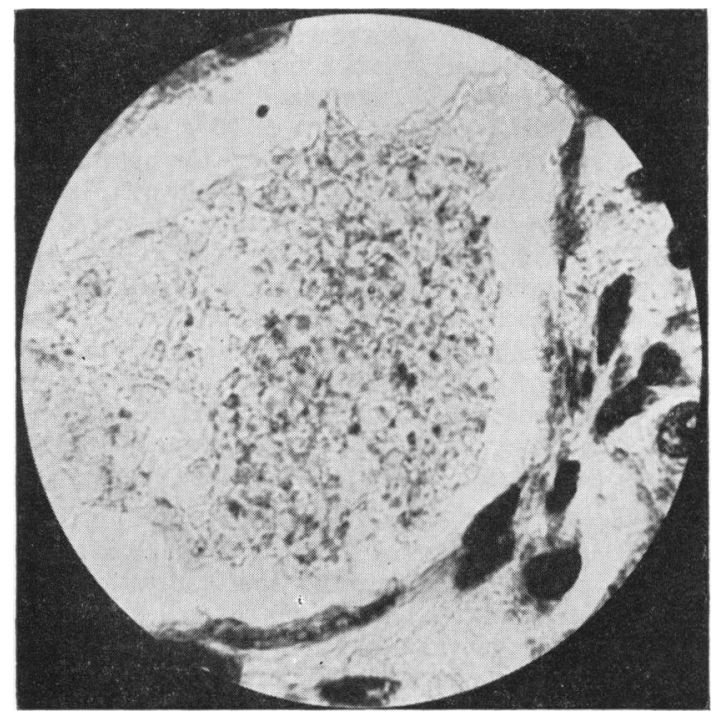

FIG. 5.-Case 1. Section of lung, showing the foamy alveolar exudate containing cysts with several nuclei. $(\times 1,230$.)
Case 2. A male was delivered at term weighing $8 \frac{1}{2}$ lb. $(3,955$ g.) after an uneventful pregnancy. The parents and a 6-year-old brother are well; a paternal uncle, now aged 16 years, had pulmonary tuberculosis at the age of 4 years. The only previous history of ill health was a mild short respiratory illness with cough, wheeze and fever at the age of 10 months. At the age of 21 months he suffered a respiratory illness which was gradual in onset with anorexia, lethargy, cough, pyrexia, dyspnoea and cyanosis. This responded three weeks later to tetracycline. On September 5, 1959, at the age of 2 years, he was transferred to The Hospital for Sick Children because of a sudden recurrence of his previous symptoms three weeks previously.

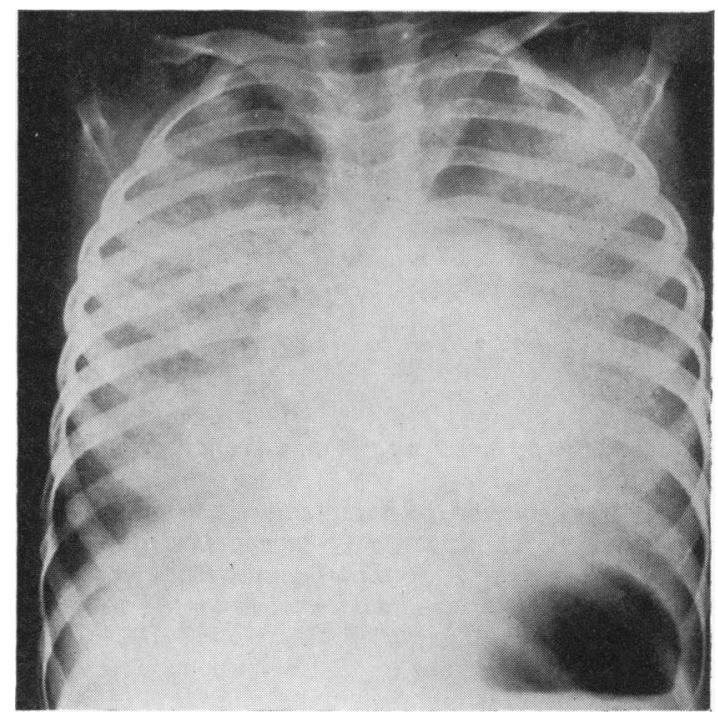

FIG. 6.-Radiograph of Case 2, three weeks before starting treatment with pentamidine.

On examination there was moderate cyanosis, clubbing of fingers and toes, dyspnoea with use of accessory muscles of respiration and a respiratory rate of $60 / \mathrm{min}$. The percussion note of the chest was unimpaired. The breath sounds were normal and there were no adventitious sounds. The heart was not clinically enlarged and no murmurs were heard. Blood pressure was $120 / 75 \mathrm{~mm}$. Hg. No lymphadenopathy, hepatosplenomegaly or pallor were noted. Chest radiography on September 7, 1959, showed very widespread consolidation throughout lungs with a sparing of the periphery of both lower zones (as in Fig. 6). Gastric washings showed epithelial and inflammatory cells present, but no pneumocystis, tubercle bacilli or haemosiderosis.

In view of the physical and radiological findings a diagnosis of Pneumocystis carinii pneumonia was made. Lung biopsy by thoracotomy was performed by $\mathrm{Mr}$. David Waterston on September 17, 1959. There was considerable interstitial infiltration of the alveolar septa 
with mononuclear cells (Fig. 7), largely monocytic histiocytes with only very few plasma cells, lymphocytes and eosinophils. There was cuboidal hyperplasia of the alveolar endothelial cells, some of which were grossly enlarged, 'blown up' and desquamated. Extensive accumulation in the air sacs of a peculiar fluid exudate of honeycomb appearance (Fig. 8) was seen, and there were numerous pinpoint basophilic dots in it. Special silver impregnation stains showed typical Pneumocystis carinii cysts and free parasites in the alveolar exudate (Fig. 9). Cultures of bronchial secretions and cut surface of lung obtained at thoracotomy grew no pathogens.

The diagnosis of Pneumocystis carinii pneumonia suggested the possibility of hypogammaglobulinaemia, but the gamma globulin band on paper electrophoresis (Fig. 1) was regarded as normal for a child of this age. In spite of this the serum was analysed by the gel diffusion technique and 7S gamma globulin was found to be $30 \mathrm{mg} . / 100 \mathrm{ml}$. This discrepancy is explained later.

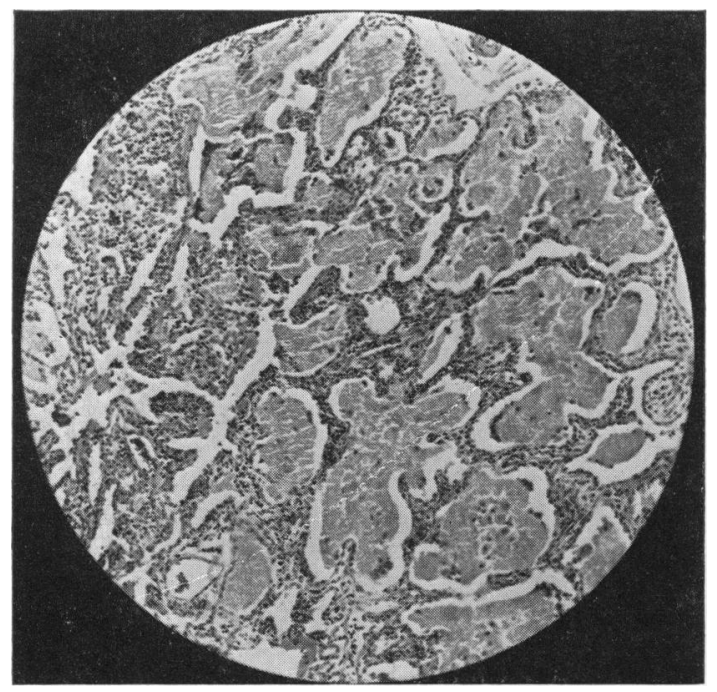

FIg. 7.-Case 2. Photomicrograph of lung biopsy to show the interstitial cellular infiltration and the alveolar exudate. ( $\times 55$.)

Treatment with gamma globulin was started on October 26, 1959, at the dosage recommended by the Medical Research Council working party on hypogammaglobulinaemia. This consisted of weekly injections of gamma globulin in a dose of $0.05 \mathrm{~g} . / \mathrm{kg}$. On December 8 , 1959 , the level of gamma globulin was $230 \mathrm{mg} . / 100 \mathrm{ml}$. In view of the lack of improvement twice weekly injections of the same amount were commenced and have continued since then with the gamma globulin concentration varying from $280 \mathrm{mg}$. $/ 100 \mathrm{ml}$. to $560 \mathrm{mg}$. $/ 100 \mathrm{ml}$.

Treatment of his respiratory condition with tetracycline, penicillin, streptomycin and potassium iodide failed to result in any improvement. His condition fluctuated a little but remained essentially critical for a period of 16 weeks when therapy with pentamidine isethionate was instituted. A total dose of $500 \mathrm{mg}$. was

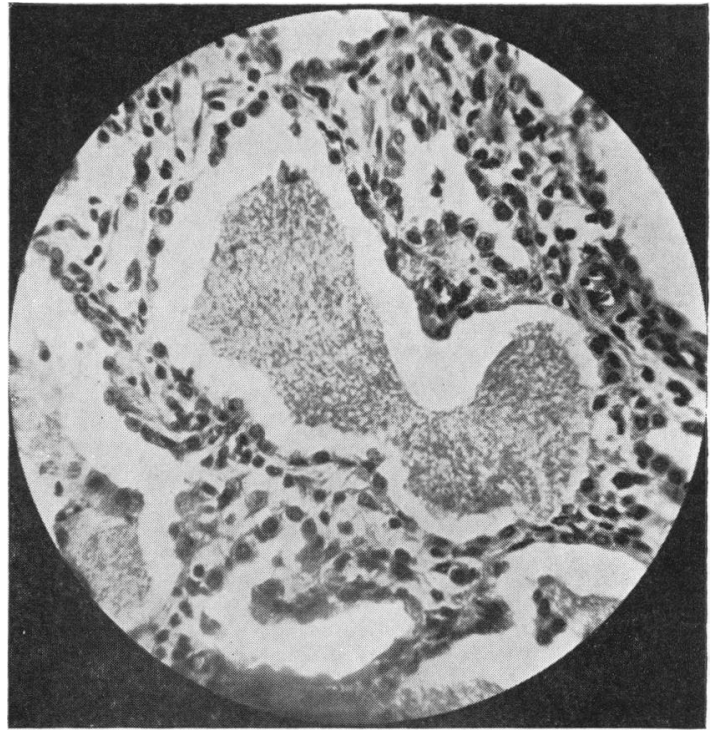

Fig. 8.-Case 2. Photomicrograph of lung biopsy $(\times 220)$. The honeycomb exudate is shown.

given in 10 daily intramuscular injections. Two days after completion of the course there was a dramatic clinical improvement. Respiratory distress subsided. His appetite improved and he became happy and active. There had been no significant change in the radiological picture for four months but considerable radiological improvement occurred 10 days later (Fig. 10) and a

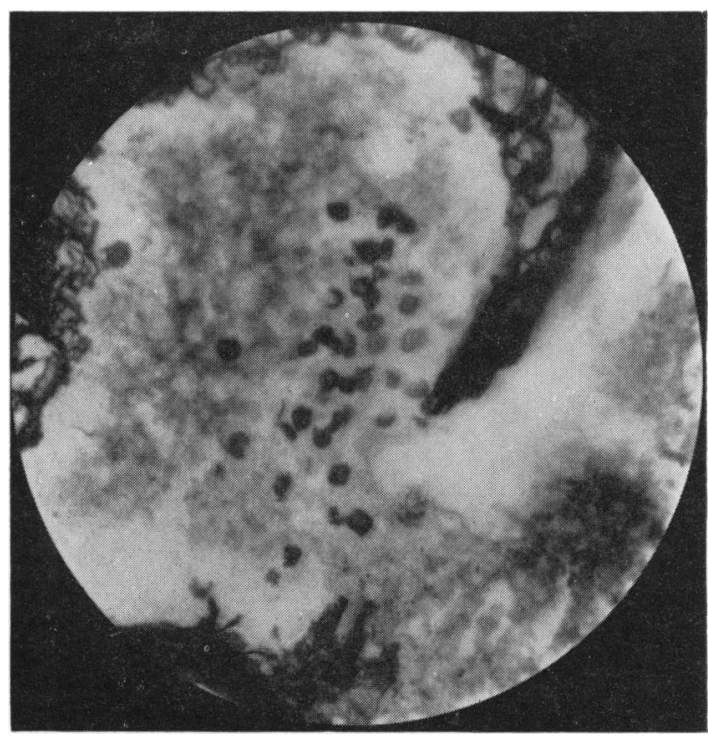

FIG. 9.- Case 2. Photomicrograph of lung. ( $\times$ 556.) Silver stain to show cystic forms of Pneumocystis carinii in the alveolar exudate. 


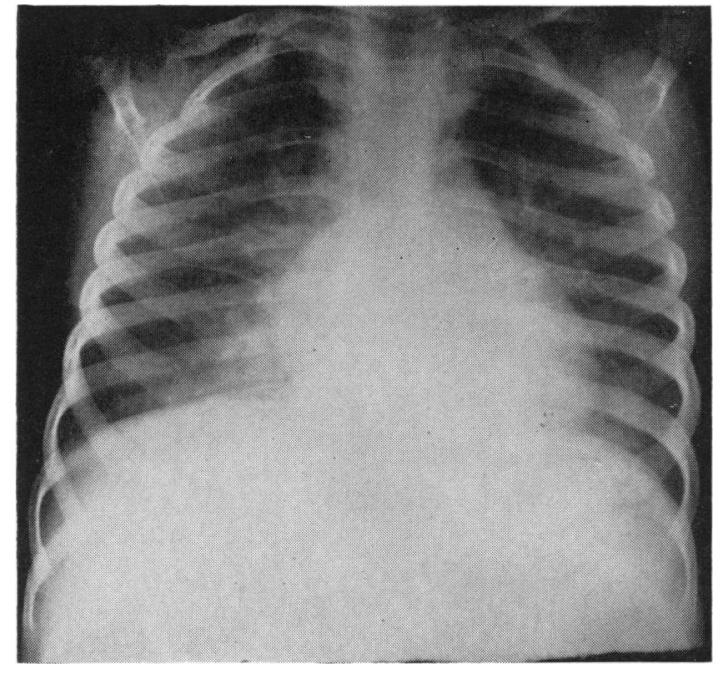

Fig. 10.-Radiograph of Case 2, taken 10 days after starting treatment.

further radiograph taken on the 28th day after completion of treatment showed minimal abnormality (Fig. 11). At further examination nine weeks later he was clinically well and chest radiographs were clear (Fig. 12). He is still continuing weekly injections of gamma globulin. He has remained well and a chest radiograph in October 1961 revealed no abnormalities.

\section{Discussion}

Pneumocystis carinii pneumonia has been well described in excellent papers by Gajdusek (1957) and

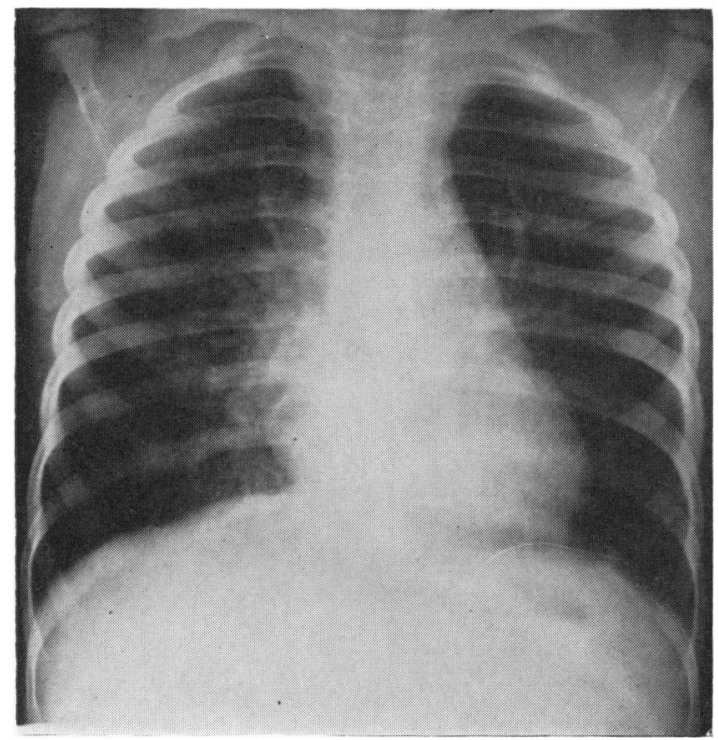

FIG. 11.-Radiogr iph of Case 2, 28 days after completion of treatment. others. Many of the features described were evident in these two cases. As is usual, the onset was insidious with troublesome cough and respiratory distress progressing to extreme tachypnoea $(60-100 / \mathrm{min}$.$) and cyanosis. It may be possible to$ conclude that in Case 2 the initial episode of respiratory symptoms, which subsided for six weeks before the second hospital admission, may have been in fact due to this disease, as Berdnikoff (1959) mentioned a few days of freedom from symptoms soon after the initial onset. He suggested that if this was a common feature of the disease it could be a useful diagnostic feature.

The cyanosis became more marked during episodes of coughing and was aggravated by raising

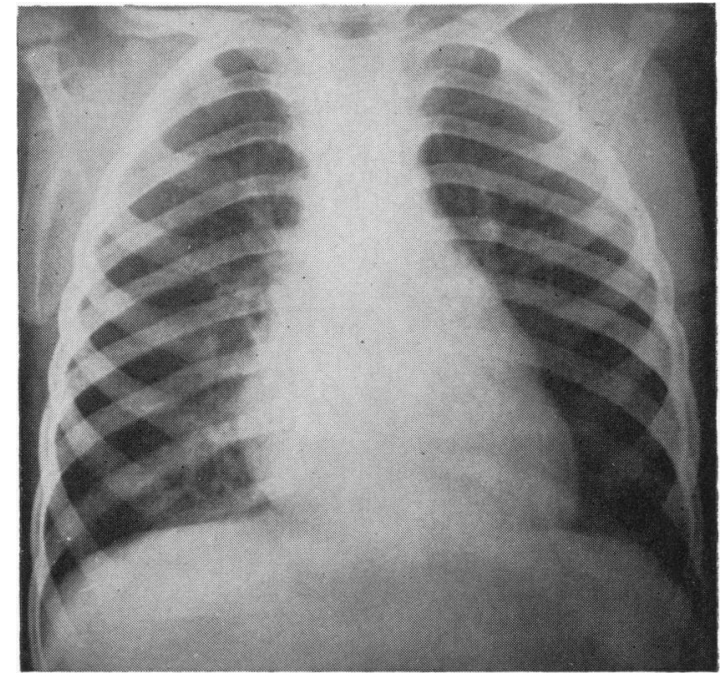

FIG. 12.-Radiograph of Case 2, 13 weeks after completion of treatment.

the flap of the oxygen tent in which the children were nursed. The disparity between the extreme respiratory distress with gross radiological changes in the lung fields and the absence of abnormal clinical signs in the chest was the most striking feature of the illness.

The temperature was either normal or slightly raised throughout the illness.

A high leucocytosis with preponderance of polymorph neutrophils was present and the sedimentation rate was only slightly raised; these features have been observed previously. There was no anaemia and the raised levels of serum calcium reported by Ahvenainen (1957) were not present in Case 2.

The chest radiographs in these two cases showed 
a fairly distinctive pattern with widespread infiltration of the lung fields, most striking in the hilar regions. The process was diffuse and not lobar in distribution, and there was no involvement of the pleura. An 'air bronchogram' was visible.

Diagnosis of the condition seems to be only satisfactorily made by lung biopsy. Gellis (1958) recommends the use of needle biopsy in these cases, but the specimen in Case 2 was obtained by open thoracotomy. Reports of the identification of the organism in sputum and tracheal aspirate are rare. The organism has not been found in gastric washings, urine or faeces. Systemic dissemination has been reported (Zandanell, 1954), and there are two accounts of finding the organism in a thick smear of peripheral blood (Gajdusek, 1957). The complement-fixation test reported by Vivell, Buhn and Lips (1956) was not used in these cases. They demonstrated antibodies by complement fixation using extract from the lungs of affected infants. They regard a titre of $1: 4$ as positive, but a rising antibody titre would be more conclusive than a single positive test. A positive reaction usually occurred during the second week of the illness. A large series was reported with positive results in $8 €-100 \%$ of cases. Of exposed, clinically well infants, $9-37 \%$ had positive titres but random testing of well infants and adults only showed $1 \cdot 4-6 \%$ of positive titres. There are no reports of titres in patients who have hypogammaglobulinaemia; it may well be that complement-fixing antibodies in such patients are poorly or not developed, and hence of little value.

The occurrence of cases during an epidemic with the appearance of the typical clinical picture and $\mathrm{x}$-ray changes makes for easy clinical diagnosis. Isolated cases must be differentiated from lipoid pneumonia, primary atypical pneumonia, Friedlander's pneumonia and such conditions as pulmonary haemosiderosis, diffuse pulmonary fibrosis of the Hamman-Rich type and histiocytic reticuloendotheliosis.

In 1938 Ammich, in Europe, first described the characteristic pulmonary pathology of infants dying of interstitial plasma cell pneumonia, although it had been recognized earlier in Germany as a clinico-pathological state. Many reports followed showing the widespread distribution of this type of pneumonia in Central, Southern and Northern European countries. Vaněk (1951) described this protozoon in the lungs of infants dying with the clinical and histological features of plasma cell pneumonia and considered it to be the probable aetiological agent.

The disease reported in these countries affects chiefly full-term debilitated infants and premature babies with a maximum incidence between 6 weeks and 4 months. There is an equal sex incidence. The mortality rate varies considerably in the reports but appears to be between 20 and $50 \%$. When recovery occurs it is thought there are no sequelae. The incubation period has been estimated to be about 40 days (Gerrard, 1958).

Isolated cases have occurred in Great Britain since Baar (1955) described the first case and Lunseth, Kirmse, Prezyna and Gerth (1955) reported the first case from the United States. Further reports have occurred in these countries, together with cases from Canada and Australia. Reports of approximately 40 cases have now appeared in these countries.

Eight cases reported by Hutchison (1955), Gerrard and Moore (1957), Bird and Thomson (1957), Eberling and Cohen (1958), McKay and Richardson (1959), Burke, Krovetz and Good (1961), were all male and had low levels of circulating gamma globulin. In a further five cases there is suggestive evidence of hypogammaglobulinaemia. In the cases of Hutchison and Gerrard and Moore there were brothers who died of pneumocystis pneumonia at the ages of 6 months and 8 months. Howard and Sheldon (1958) describe a case in which no plasma cells were seen and there was lymphoid depletion of the spleen. Russell (1959) reports a case in a girl who died at 5 months, and on paper electrophoresis gamma globulin was just detected, and isohaemagglutinins were reduced.

TABLE 1

\begin{tabular}{|c|c|c|}
\hline & Case 1 & Case 2 \\
\hline 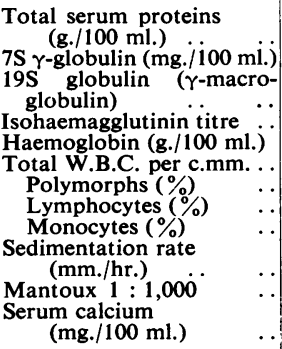 & $\begin{array}{c}6 \\
100 \\
50 \% \text { of standard } \\
\text { normal serum } \\
1 \cdot 0 \\
12 \cdot 1 \\
23,400 \\
47 \\
50 \\
3 \\
14 \\
\text { Negative } \\
-\end{array}$ & $\begin{array}{c}6 \cdot 1 \\
30 \\
1,000 \% \text { of standard } \\
\text { normal serum } \\
512 \\
14 \cdot 8 \\
21,500 \\
35 \\
60 \\
5 \\
7 \\
\text { Negative } \\
9 \cdot 6\end{array}$ \\
\hline
\end{tabular}

The Serum Protein Abnormalities. As shown in Table 1, the following serum protein abnormalities were found. The first patient has low 7S gamma globulin and slightly reduced $19 \mathrm{~S}$ gamma globulin (gamma macroglobulin). This latter protein is one of the two other proteins, besides the 7S gamma globulin, that are sometimes, but not always, deficient in the serum of patients with hypogammaglobulinaemia (Gitlin, Hitzig and Janeway, 1956). 
In our second patient the diagnosis of hypogammaglobulinaemia was established in spite of an apparently normal gamma globulin band on paper electrophoresis. The electrophoretic gamma globulin band includes both the predominant $7 \mathrm{~S}$ gamma globulin, which is associated with most antibody function, and the gamma macroglobulin which is associated, amongst other functions, with the isoagglutinin activity. The gel diffusion precipitin technique, which estimates these two proteins independently, showed that the 7S gamma globulin was low $(30 \mathrm{mg} . / 100 \mathrm{ml}$.), whereas the gamma macroglobulin was very high, $100 \%$ of the concentration in the standard serum from a healthy adult male. The conversion of these results to $\mathrm{mg}$./ $100 \mathrm{ml}$. is not precisely known but a figure of $50 \mathrm{mg}$./ $100 \mathrm{ml}$. for the standard is a reasonable approximation. This gives a concentration of $500 \mathrm{mg}$./ $100 \mathrm{ml}$. in the serum of our patient. Thus, the total gamma globulin concentration would be $530 \mathrm{mg}$./ $100 \mathrm{ml}$., quite enough to produce a qualitatively normal gamma globulin band on paper electrophoresis. This interpretation has been confirmed by ultracentrifugal analyses (see Kekwick, Vallet, Cutbush, Mollison, Thomas, Gell and Soothill, 1961).

This limitation in the electrophoretic technique

TABLE 2

VARIATION IN LEVELS OF 7S AND $\gamma$-MACROGLOBULIN DURING TREATMENT OF C.B. (Case 2)

\begin{tabular}{c|c|c}
\hline Date & $\begin{array}{c}\text { 7S } \gamma \text {-globulin } \\
\text { (mg./100 ml. })\end{array}$ & $\begin{array}{c}\gamma \text {-macroglobulin } \\
\text { of Standard Serum) }\end{array}$ \\
\hline 12.10 .59 & 30 & 1,000 \\
20.10 .59 & 70 & 1,000 \\
26.11 .59 & 240 & 1,000 \\
11.1 .60 & 560 & 300 \\
6.2 .60 & 360 & 250 \\
9.2 .60 & 480 & 125 \\
9.1 .61 & 280 & 400 \\
31.1 .61 & 240 & 250 \\
15.5 .61 & 400 & 800 \\
\hline
\end{tabular}

for diagnosing hypogammaglobulinaemia must be borne in mind when a very strong clinical suspicion of hypogammaglobulinaemia is not confirmed by paper electrophoresis. Another interesting point is the very high titre of isoagglutinin activity. The excess gamma macroglobulin in this patient is evidently capable of performing this antibody-like function normally, in contrast to the abnormal 19S gamma globulin in the serum of patients with macroglobulinaemia (J. F. Soothill, D. R. Stanworth and P. Ratcliff, 1962, personal communication).

While under treatment with gamma globulin a satisfactory $7 \mathrm{~S}$ gamma globulin concentration was achieved by the injections (see Table 2). The gamma macroglobulin concentration in the serum of C.B. fell steadily, but more recently the concentration has increased again. We have no explanation of these changes, and there is no clinical evidence of recurrence of the Pneumocystis carinii infection. In fact there is no reason to relate the high concentration of gamma macroglobulin to this infection, as our first case, though capable of producing gamma macroglobulin, did not show a rise of the concentration, and Rosen, Kevy, Merler, Janeway and Gitlin (1961) have reported this rise in patients with hypogammaglobulinaemia, without this infection.

Seven proven cases of congenital hypogammaglobulinaemia and five more possible cases reported with infection with this protozoon suggest that the lowered levels of gamma globulin may make patients more susceptible to infection with Pneumocystis carinii. The infection in adults in association with generalized involvement of the reticuloendothelial system may be associated with a deficiency in gamma globulin synthesis. The particular age incidence of the disease affecting infants in European countries would coincide with the period of neonatal physiological hypogammaglobulinaemia. No reports of very low gamma globulin levels have been made in these cases, however.

The absence of plasma cells in hypogammaglobulinaemia would mean that interstitial plasma cell pneumonia in cases of the disease in these patients is a misnomer. In fact, the cellular infiltration in such cases tends to be histiocytic in type.

The rarity of secondary pyogenic infection in the reported cases of hypogammaglobulinaemia and Pneumocystis carinii infection is unusual, but may be due to the widespread use of antibiotics given in an attempt to cure the pulmonary infection.

Treatment. The great variety of the agents used in this condition is an indication of the unsatisfactory treatment. Antibiotics, corticotrophin, corticosteroids, gamma globulin and blood transfusions, radiographs and short-wave therapy have been used without any apparent effect. Oestrogens, chloroquine, quinine, primaquine, emetine hydrochloride and paludrine likewise have not been successful.

Ivády and Páldy (1958) explored the possibility of agents that have an antiprotozoal and antifungal effect. They used aromatic diamidines and pentavalent antimony compounds that have proved effective in trypanosomiasis and kala azar. Treating 19 cases (14 with 'neostibosan' (a quinquivalent antimony complex mixture containing p-aminobenzenestibonic acid, p-acetamidobenzenestibonic 
acid, antimonic acid and diethylamine), four with pentamidine $(4: 4$ '-diamidino-diphenoxypentane di$\beta$-hydroxyethane sulphonate) and one with stilbamidine (4:4'-diamidinstilbene di-2-hydroxyethane sulphonate)) recovery was reported in 16 cases. The three fatal cases were moribund when treatment commenced and 'neostibosan' was used. At autopsy two of the cases showed extensive bronchopneumonia as well as the characteristic changes of Pneumocystis carinii pneumonia. They stressed the importance of early treatment and the use of broad spectrum antibiotics in cases complicated by bronchopneumonia.

Stilbamidine was used intravenously in a daily dose of $4 \mathrm{mg}$. $/ \mathrm{kg}$. for 10 days and pentamidine as a daily intramuscular injection in the same dose for 10 days. Neostibosan was not calculated in relation to body weight but given as a daily intramuscular injection of $0.05 \mathrm{~g}$. for $10-12$ days in a $10 \%$ aqueous solution.

Because of this encouraging report we treated our second patient with pentamidine as described above in a dose of $4 \mathrm{mg} . / \mathrm{kg}$. No side-effects were observed. It is impossible to say what role gamma globulin has played in the response to treatment, but previous use of this agent alone, or in combination with other agents, has never been effective.

The long duration of the illness raised the possibility of a natural remission and the response that occurred immediately after treatment may be coincidental. The treatment of further cases with these drugs would have to be carried out before the value could be established.

\section{Summary}

Two case histories of patients with congenital hypogammaglobulinaemia who developed Pneumocystis carinii pneumonia are described.

In one, paper electrophoresis of the serum gave an apparently normal gamma globulin band in spite of the fact that immunochemical methods gave very low values for the gamma globulin; this was at least partly due to a very high concentration of gamma macroglobulin.

Treatment with pentamidine and gamma globulin appears to have been effective in one case.

We wish to record our thanks to Dr. P. R. Evans for his encouragement and permission to publish these cases; to Dr. J. F. Soothill for helpful criticism and estimation of serum proteins; to Dr. P. L. Mollison for estimation of isohaemagglutinin titres.

We also wish to thank Mr. Derek Martin for the photographs.

\section{REFERENCES}

Ahvenainen, E. K. (1957). Interstitial plasma cell pneumonia.

Pediat. Clin. N. Amer., 4, 203.
Ammich, O. (1938). Uber die nichtsyphilitische interstitielle Pneumonie des ersten Kindesalters. Virchows Arch. path. Anat., 302, 539.

Baar, H. S. (1955). Interstitial plasmacellular pneumonia due to pneumocystis carinii. J. clin. Path., 8, 19.

Berdnikoff, G. (1959). Fourteen personal cases of pneumocystis carinii pneumonia. Canad. med. Ass. J., 80, 1.

Bird, T. and Thomson, J. (1957). 'Pneumocystis carinii' pneumonia. Lancet, 1, 59.

Burke, B. A., Krovetz, L. J. and Good, R. A. (1961). Occurrence of Pneumocystis carinii pneumonia in children with agammaglobulinemia. Pediatrics, 28, 196.

Eberling, E. W. and Cohen, F. (1958). Pneumocystis carinii pneumonia: report of a case from Southwestern United States.

ibid., 21, 345.
Flynn, F. V. and de Mayo, P. (1951). Micro-electrophoresis of protein on filter-paper. Lancet, $2,235$.

Gajdusek, D. C. (1957). Pneumocystis carinii-etiologic agent of interstitial plasma cell pneumonia of premature and young infants. Pediatrics, 19, 543.

Galloway, W. H. and McBean, L. M. (1956). Generalized vaccinia. Brit. med.J., 2, 1102.

Brit. (1958). Generalized vaccinia in infancy; a report of four cases. ibid., 2, 490.

Gellis, S. S (1958). Year Book of Pediatrics (1958-59 Series), p. 243. Yearbook Publishers, Chicago.

Gerrard, J. W. (1958). Pneumocystis pneumonia. Pediat. Clin. N. Amer., 5, 327.

and Moore, D. F. (1957). Interstitial plasma cellular pneumonia due to Pneumocystis carinii. Canad. med. Ass. J., 76, 299.

Gitlin, D., Hitzig, W. H. and Janeway, C. A. (1956). Multiple serum protein deficiencies in congenital and acquired agammaprotein deficiencies in congenital and
globulinemia. J. clin. Invest., 35, 1199.

Howard, R. M. and Sheldon, W. H. (1958). Pneumocystis pneumonia: report of a case. A.M.A. J. Dis. Child., 95, 18.

Hutchison, J. H. (1955). Congenital agammaglobulinaemia. Lancet, 2, 844, 1196.

Ivády, G. and Páldy, L. (1958). Ein neues Behandlungsverfahren der interstitiellen plasmazelligen Pneumonie Frühgeborener mit fünfwertigem Stibium und aromatischen Diamidinen. Mschr. Kinderheilk., 106, 10.

Kekwick, R. A., Vallet, L., Cutbush, M., Mollison, P. L., Thomas, A. R., Gell, P. G. H. and Soothill, J. F. (1961). Estimation of gamma globulin in the serum of patients with hypogammaglobulinaemia. J. clin. Path., 14, 470.

Lunseth, J. H., Kirmse, T. W., Prezyna, A. P. and Gerth, R. E. (1955). Interstitial plasma cell pneumonia. J. Pediat., 46, 137.

McKay, E. and Richardson, J. (1959). Pneumocystis carinii pneumonia associated with hypogammaglobulinaemia. Lancet, $2,713$.

Mollison, P. L. (1956). Blood Transfusion in Clinical Medicine, 2nd ed. Blackwell Scientific Publications, Oxford.

Rosen, F. S., Kevy, S. V., Merler, E., Janeway, C. A. and Gitlin, D. (196i). Recurrent bacterial infections and dysgammaglobulinemia: Deficiency of $7 \mathrm{~S}$ gamma-globulins in the presence of elevated 19S gamma-globulins. Pediatrics, 28, 182 .

Russell, J. G. B. (1959). Pneumocystis pneumonia associated with agammaglobulinaemia. Arch. Dis. Childh., 34, 338.

Soothill, J. F. (1962). Estimation of eight serum proteins by a gel diffusion precipitin technique. J. Lab. clin. Med., 59, 859.

Vaněk, J. (1951). Atypická ('intersticiálni') pneumonie dětí, vyvolaná Pneumocystis Carinii. Cas. Lék. čes., 90, 1121.

Vivell, O.. Buhn, W. H. and Lips, G. (1956). Erfahrungen mit der serologischen Diagnose der interstitiellen plasmacellulären Pneumonie von jungen Säuglingen und Früngeburten. $Z$.

Kinderheilk., 78, 653.
Wilkinson, R. H. (1960). Chemical Micromethods in Clinical Medicine. Charles C. Thomas, Springfield, Illinois.

Zandanell, E. (1954). Pneumozystisbefund ausserhalb der Lunge bei interstitieller plasmazellulärer Pneumonie der Säuglinge und Frühgeburten. Zbl. allg. Path. path. Anat., 92, 74. 